\title{
ON SOLVABILITY OF SOME NONLINEAR FRACTIONAL INTERVAL INTEGRAL EQUATIONS
}

\author{
SÜMEYYE ÇAKAN AND ÜMIT ÇAKAN
}

\begin{abstract}
In this paper, firstly we deal with solvability of a first kind nonlinear interval integral equation of fractional order. Then we present a theorem giving sufficient conditions for existence of solution of a second kind nonlinear interval integral equation of fractional order in the space of continuous interval-valued functions on the interval $[a, b]$ by using Banach fixed point theorem. We give also some examples satisfying the conditions of our main theorems.
\end{abstract}

Mathematics subject classification (2010): 28B20, 45M99, 47H09, 47H10.

Keywords and phrases: Interval-valued function; Interval integral equations; Nonlinear integral equations; Banach fixed point theorem; Existence of solutions.

\section{REFERENCES}

[1] S. ARShAD AND V. Lupulescu, On the fractional differential equations with uncertainty, Nonlinear Anal. 74, (2011), 3685-3693.

[2] J.P. Aubin And H. Frankowska, Set-Valued Analysis, Birkhauser, Boston, 1980.

[3] R.J. Aumann, Integrals of set-valued functions, J. Math. Anal. Appl. 12, (1965), 1-12.

[4] S. Chandrasekhar, Radiative Transfer, Oxford Univ. Press, London, 1950.

[5] G. Gripenberg, On some epidemic models, Quart. Appl. Math. 39, (1981), 317-327.

[6] F. HiAI, H. UMEGAKI, Integrals, conditional expectations and martingales of multivalued functions, J. Multivar. Anal. 7, (1977), 149-182.

[7] E. KREYSZIG, Introductory Functional Analysis with Applications, John Wiley-Sons Inc., New York (1989).

[8] V. Lakshmikantham, T. Gnana Bhaskar and J. Vasundhara DeVi, Theory of set differential equations in metric spaces, Cambridge Scientific Publ., Florida, 2006.

[9] V. Lupulescu, Fractional calculus for interval-valued functions, Fuzzy Sets and Systems 265, (2015), 63-85.

[10] V. Lupulescu AND N.V. HoA, Interval Abel Integral Equations, Soft Comput. doi:10.1007/s00500015-1980-2, (2016).

[11] M.T. Malinows KI, Interval differential equations with a second type Hukuhara derivative, Appl. Math. Lett. 24, (2011), 2118-2123.

[12] S. MARKov, Calculus for interval functions of a real variables, Computing 22, (1979), 325-337.

[13] R.E. Moore, R.B. Kearfott and M.J. Cloud, Introduction to Interval Analysis, SIAM, Philadelphia, 2009.

[14] S. SALAHSHOUR AND M. KHAN, Exact solutions of nonlinear interval Volterra integral equations, Int. J. Ind. Math. 4, Article ID: IJIM-00291, (2012).

[15] S.G. Samko, A.A. Kilbas, O.I. Marichev, Fractional integrals and derivatives: theory and applications, Gordon and Breach Science Publishers, Switzerland, 1993.

[16] Y. SHEN, The Cauchy type problem for interval-valued fractional differential equations with the Riemann-Liouville gH-fractional derivative, Adv. Difference Equ. doi:10.1186/s13662-016-0827-1, (2016).

[17] L. STEFAnini, A generalization of Hukuhara difference and division for interval and fuzzy arithmetic, Fuzzy Sets and Systems 161, (2010), 1564-1584. 
[18] L. STEFANINI AND B. BeDE, Generalized Hukuhara differentiability of interval valued functions and interval differential equations, Nonlinear Anal. 71, (2009), 1311-1328. 